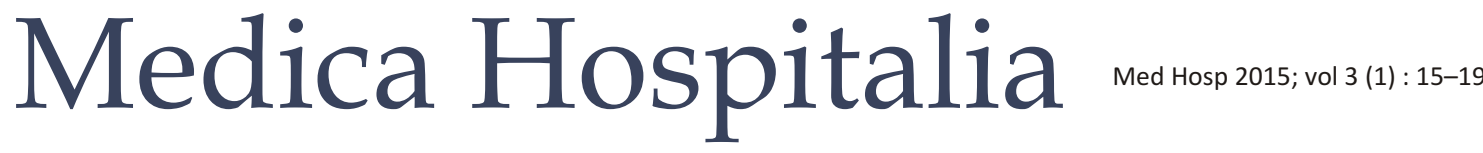

Original Article

\section{Hubungan Pengetahuan dengan Perilaku Pelajar Pengguna Personal Listening Devices (PLDs)}

\author{
Muyassaroh, Dimas, Citra \\ Departemen IKTHT-KL Fakultas Kedokteran Universitas Diponegoro Semarang
}

\begin{abstract}
Abstrak
Latar belakang : Pelajar SMA/sederajat sebagian besar memiliki hobi mendengarkan musik menggunakan personal listening devices (PLDs). Penggunaan PLDs meningkatkan risiko kurang pendengaran sensorineural (KPSN) akibat bising. Pengetahuan yang baik tentang PLDs akan menurunkan risiko KPSN. Penelitian ini bertujuan untuk menganalisis hubungan pengetahuan dengan perilaku pelajar pengguna PLDs.

Metode : Survey pengguna PLDs pada pelajar SMA/sederajat di kota Semarang bulan Mei 2014. Pengambilan data dilakukan dengan pengisian kuesener terpimpin yang telah diujicobakan. Data dianalisis dengan uji korelasi Spearman.

Hasil : Subyek penelitian sebanyak 308 sampel, laki-laki 191 $(62,0 \%)$ dan perempuan 117 (38,0\%). Rerata skor pengetahuan $8,17 \pm 1,96$ sedangkan rerata skor perilaku $5,35 \pm 2,29$. Skor pengetahuan berhubungan dengan skor perilaku $(p=0,000)$ dengan tingkat korelasi lemah ( $r=0,295)$.

Simpulan : Terdapat hubungan pengetahuan dengan perilaku pelajar pengguna PLDs.
\end{abstract}

Kata kunci : Personal listening devices, pengetahuan, perilaku

\section{Relationship between knowledge and attitude of Personal Listening Devices (PLDs) users}

\author{
Abstract
}

Background : Students of senior high school have more tendencies to use personal listening devices (PLDs) when listening to their music. PLDs use increases the risk of sensorineural hearing loss (SNHL) due to the noise. Better knowledge of PLDs will reduce the risk of SNHL. The primary objective of this study was to analyze the relationship between knowledge of PLDs and student's behavior.

Methods : Survey of PLDs users on senior high school students in Semarang in May 2014. Data were collected by questionnaire. Data were analyzed with the Spearman correlation test.

Results : The study subjects were 308 samples, 191 men (62.0\%) and 117 women (38.0\%). The mean knowledge score was $8.17 \pm$ 1.96 while the mean behavior score was $5.35 \pm 2.29$. The knowledge score have correlation with the behavior score $(p=0.000)$ with weak correlation degree $(r=0.295)$.

Conclusion : There is a correlation between knowledge of PLDs and student's behavior.

Keywords : Personal listening devices, knowledge, behavior.

\section{PENDAHULUAN}

Penggunaan personal listening devices (PLDs) seperti MP3 player dan handphone semakin populer di seluruh dunia. PLDs generasi baru mempunyai kemampuan baterai yang tahan lama sehingga memungkinkan pengguna mendengarkan musik dalam jangka waktu lama dan volume suara yang lebih keras. ${ }^{1}$ Penggunaan PLDs juga semakin popular di Indonesia. PLDs sudah menjadi kebutuhan umum yang harus dimiliki oleh para remaja. Level suara maksimum yang dihasilkan PLDs dapat mencapai $110-120 \mathrm{~dB} .{ }^{1}$ Penggunaan PLDs ini berpotensi meningkatkan risiko kurang pendengaran sensorineural (KPSN) akibat bising. Banyak pengguna PLDs terutama remaja berperilaku tidak aman dalam menggunakan PLDs dan diperkirakan lebih dari 10\% mengalami kerusakan pendengaran permanen., ${ }^{2,3}$
Pengetahuan tentang penggunaan PLDs yang aman penting diketahui oleh para remaja terutama siswa SMA. Taljaard melakukan pengamatan selama 3 bulan tentang perubahan perilaku penggunaan PLDs pada remaja setelah diberikan edukasi. Pemberian edukasi ini terbukti dapat merubah perilaku remaja yang awalnya tidak aman menjadi lebih aman. ${ }^{4}$ Tujuan dari penelitian ini adalah menganalisis hubungan pengetahuan dengan perilaku pelajar pengguna PLDs.

\section{METODE}

Penelitian ini merupakan survei dengan desain penelitian belah lintang yang dilaksanakan pada bulan Mei 2014. Subyek penelitian adalah siswa SMA pengguna PLDs usia 15-19 tahun dari 5 sekolah yang dipilih secara acak dari daftar SMA di kota Semarang. 
Pengambilan data dilakukan dengan pengisian kuesener terpimpin yang telah diujicobakan pada 20 siswa pengguna PLDs di salah satu SMA.

Kuesioner penelitian terdiri dari 9 pertanyaan tentang pengetahuan penggunaan PLDs dengan rentang total skor 0-12 dan 5 pertanyaan tentang perilaku penggunaan PLDs dengan rentang total skor 0-10. Cara kerja penelitian dimulai dengan pengisian persetujuan mengikuti penelitian dilanjutkan pengisian kuesioner yang berisi pertanyaan tentang pengetahuan dan perilaku penggunaan PLDs secara terperinci. Hubungan pengetahuan dengan perilaku penggunaan PLDs dianalisis dengan uji korelasi Spearman. Tingkat kemaknaan ditentukan pada nilai $p<0,05$ dengan confident interval (CI) $95 \%$.

\section{HASIL}

Subyek penelitian sebanyak 308 sampel, terdiri dari 191 laki-laki $(62,0 \%)$ dan 117 perempuan $(38,0 \%)$.

Hasil kuesioner tingkat pengetahuan didapatkan 95,8\% sampel mengetahui bahwa PLDs dapat menimbulkan gangguan pendengaran tetapi $14 \%$ sampel tidak mengetahui jenis gangguan pendengaran yang ditimbulkan. 48,7\% sampel masih menganggap bahwa kurang pendengaran akibat PLDs bersifat sementara dan dapat kembali normal. 51,3\% sampel mengetahui jenis earphone yang aman untuk PLDs.

Hasil kuesioner perilaku didapatkan 20,5\% sampel berperilaku tidak aman dalam penggunaan PLDs yaitu durasi penggunaan $>2 \mathrm{jam} /$ hari dan $82,8 \%$ sampel menggunakanjenis earphone earbud/canal phone.

Rerata skor pengetahuan adalah 8,17 \pm 1,96 sedangkan rerata skor perilaku adalah 5,35 $\pm 2,29$. Skor pengetahuan berhubungan secara signifikan dengan skor perilaku $(p=0,000)$ dengan tingkat korelasi lemah $(r$ $=0,295$ ).

\section{PEMBAHASAN}

Hasil penelitian didapatkan rata-rata skor pengetahuan adalah $8,17 \pm 1,96$ dari skor total 12 . Artinya jika dilakukan persentase didapatkan $68,1 \%$ pelajar mengetahui tentang penggunaan PLDs dan masih cukup tinggi para pelajar yang belum mengetahui $(31,9 \%)$ tentang PLDs dan segala efek yang ditimbulkannya. Sebanyak 95,8\% responden mengetahui bahwa PLDs dapat menimbulkan gangguan pendengaran namun

\section{TABEL 1}

\section{Tabel distribusi masing-masing pertanyaan pengetahuan $(n=308)$}

\begin{tabular}{|c|c|c|c|}
\hline Isi kuisioner & Pengetahuan & $n$ & $\%$ \\
\hline \multirow[t]{2}{*}{ Tahu tentang PLDs } & Ya & 279 & 90,6 \\
\hline & Tidak & 29 & 9,4 \\
\hline \multirow[t]{2}{*}{ Efek PLDs thd pendengaran } & Ya & 218 & 70,8 \\
\hline & Tidak & 90 & 29,2 \\
\hline \multirow[t]{2}{*}{ PLDs menimbulkan gangguan pendengaran } & Ya & 295 & 95,8 \\
\hline & Tidak & 13 & 4,2 \\
\hline \multirow[t]{3}{*}{ Jenis gangguan pendengaran akibat PLDs } & KP dan berdenging & 218 & 70,8 \\
\hline & KP saja & 47 & 15,2 \\
\hline & Tidak tahu & 43 & 14 \\
\hline \multirow[t]{2}{*}{ Efek gangguan pendengaran akibat PLDs } & Tidak kembali normal & 158 & 51,3 \\
\hline & Dapat kembali normal & 150 & 48,7 \\
\hline \multirow[t]{2}{*}{ Apakah tahu KP akibat PLDs dapat dicegah } & Ya & 267 & 86,7 \\
\hline & Tidak & 41 & 13,3 \\
\hline \multirow[t]{2}{*}{ Telinga berdenging tanda awal paparan bising } & Ya & 264 & 85,7 \\
\hline & Tidak & 44 & 14,3 \\
\hline \multirow[t]{4}{*}{ Gejala dini KP } & Menambah volume radio/TV & 135 & 43,8 \\
\hline & Sering mengulang kata "apa" & 234 & 76,0 \\
\hline & Sering gumam/bicara tidak jelas & 45 & 14,6 \\
\hline & Tidak tahu & 36 & 11,7 \\
\hline \multirow[t]{2}{*}{ Jenis earphone yang aman untuk PLDs } & Circum aural, supra aural & 158 & 51,3 \\
\hline & Earbud, canal phone & 150 & 48,7 \\
\hline
\end{tabular}


TAB트 2

Tabel distribusi masing-masing pertanyaan perilaku

\begin{tabular}{|c|c|c|c|}
\hline Isi kuisioner & Perilaku & $n$ & $\%$ \\
\hline \multirow[t]{3}{*}{ Durasi menggunakan PLDs dalam sehari } & $<1$ jam & 141 & 45,8 \\
\hline & 1-2 jam & 104 & 33,7 \\
\hline & $>2$ jam & 63 & 20,5 \\
\hline \multirow[t]{2}{*}{ Jenis earphone yang digunakan } & Circum aural/supra aural & 53 & 17,2 \\
\hline & Earbud/canal phone & 255 & 82,8 \\
\hline \multirow[t]{3}{*}{ Tindakan bila terjadi gangguan dengar PLDs } & Ke dokter & 281 & 91,2 \\
\hline & Ke mantri/bidan & 0 & 0 \\
\hline & Tidak periksa & 27 & 8,8 \\
\hline \multirow[t]{2}{*}{ Jika sudah terjadi gangguan di telinga akibat PLDs } & Tetap memakai & 65 & 21,1 \\
\hline & Tidak memakai & 243 & 78,9 \\
\hline \multirow[t]{4}{*}{ Untuk mengurangi efek penggunaan PLDs } & $<1,5$ jam pada $80 \%$ volume & 122 & 39,6 \\
\hline & Mengurangi vol di tempat ramai & 49 & 15,9 \\
\hline & Memilih earphone yang aman & 110 & 35,7 \\
\hline & Tidak tahu & 57 & 18,5 \\
\hline
\end{tabular}

TABEL 3

Rerata skor pengetahuan dan perilaku penggunaan PLDs

\begin{tabular}{lccc} 
Kategori & Rerata Skor & Simpang Baku & Cl 95\% \\
\hline Pengetahuan tentang penggunaan PLDs & 8,17 & 1,96 & $7,95-8,39$ \\
Perilaku penggunaan PLDs & 5,35 & 2,29 & $5,18-5,52$ \\
\hline
\end{tabular}

masih terdapat $14 \%$ responden yang tidak mengetahui jenis gangguan pendengaran akibat PLDs. Hampir separuh responden $(48,7 \%)$ masih menganggap bahwa kurang pendengaran akibat PLDs bersifat sementara dan dapat kembali normal. Padahal kurang pendengaran akibat bising merupakan gangguan yang permanen. ${ }^{5,6}$ Hanya separuh responden (51,3\%) yang mengetahui jenis earphone yang aman untuk PLDs. Secara umum earphone jenis supra-aural menghasilkan intensitas suara yang lebih rendah dibandingkan earphone jenis in-the-ear (earbud) pada tingkat volume yang sama, sehingga jenis supra-aural dikatakan lebih aman mencegah NIHL. ${ }^{1}$ Namun penelitian lain menyatakan bahwa pada suasana tenang jenis earphone tidak berpengaruh terhadap tingkat volume suara yang dipilih responden, suara yang dipilih responden yang memakai in-ear earphone tidak lebih keras dibandingkan over-the-ear headphone. Tingkat volume suara yang dipilih dipengaruhi oleh suara latar (background noise) dan isolator suara yang dipakai. Suara latar yang keras akan meningkatkan tingkat volume suara yang dipilih responden, sedangkan isolator suara yang bagus akan membuat responden memilih tingkat volume suara lebih rendah. ${ }^{7}$
Rata-rata skor perilaku pada responden didapatkan 5,35 $\pm 2,29$ dari total skor 10, jika dipersentase didapatkan rata-rata skor perilaku 53,5\%. Artinya separoh dari responden masih berperilaku yang tidak aman dalam pemakaian PLDs yang berisiko terjadinya gangguan pendengaran. Perilaku tidak aman tersebut adalah penggunaan PLDs $>2$ jam/hari, penggunaan earphone jenis earbud/canalphone, dan tetap memakai PLDs walaupun sudah terjadi gangguan pendengaran. Hal ini juga didukung bahwa 18,5\% responden tidak tahu bagaimana cara untuk mengurangi atau mencegah gangguan pendengaran pada penggunaan PLDs.

Penggunaan PLDs selama $>2$ jam/hari sebanyak 20,5\%. Pemakaian PLDs setelah 1 jam akan membuat $60 \%$ pengguna mengalami temporary threshold shift, ${ }^{8}$ sehingga masih ada kecenderungan terjadi kurang pendengaran pada pelajar pengguna PLDs. Ujicoba pada kondisi tenang, $17,8 \%$ responden secara spontan memilih intensitas di atas $85 \mathrm{~dB}$ sebagai suara yang nyaman didengar, sedangkan bila pada suasana bising (dengan background noise $90 \mathrm{~dB}$ ) $40 \%$ responden memilih intensitas di atas $94 \mathrm{~dB} .{ }^{1}$ Pada intensitas tersebut bila dilakukan lebih dari 2 jam/hari maka akan menimbulkan NIHL. 


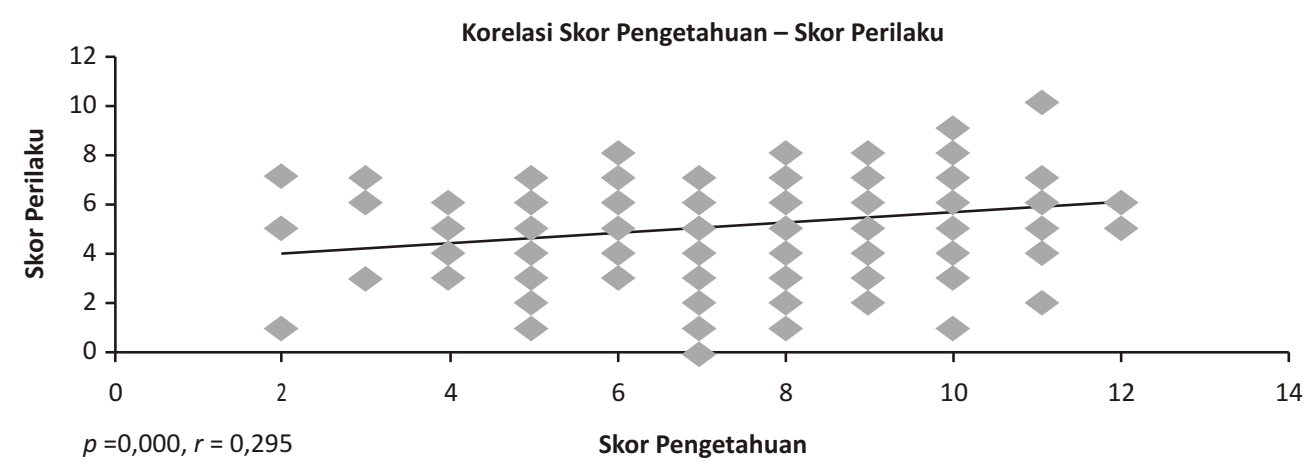

Gambar 1. Grafik korelasi skor pengetahuan-skor perilaku.

Hal ini bertambah dengan kecenderungan responden bila mendengarkan dengan tingkat volume lebih tinggi akan memakai PLDs lebih lama. ${ }^{9}$

Penelitian Breinbauer dkk merekomendasikan pemakaian PLDs dengan tingkat volume di bawah 50\% dari maksimal volume sebagai cara yang aman menghindari NIHL akibat PLDs. Pemakaian PLDs menggunakan jenis musik high-output (seperti rock, reagge, hiphop, electronic) pada tingkat volume $70 \%$ bila memakai earbud dibatasi hanya 1,4 jam/hari sedangkan bila memakai in-ear earphone (canalphone) bahkan dibatasi hanya 57 menit/ hari. ${ }^{1}$

Penggunaan jenis earphone earbud/canal phone sebanyak $82,8 \%$. Hal ini berhubungan dengan tingkat pengetahuan responden yang hanya 51,3\% mengetahui jenis earphone yang aman dipakai pada penggunaan PLDs. Earphone jenis supra-aural merupakan earphone yang relatif aman dibandingkan jenis earbud atau canalphone. Batasan pemakaian PLDs menggunakan earphone supra-aural diperbolehkan lebih lama dibandingkan earbud sebelum mencapai dosis maksimal kebisingan. Sebagai contoh pemakaian earbud pada tingkat volume $70 \%$ dengan musik high-output hanya diperbolehkan 1,4 jam/hari sedangkan pemakaian dengan supra-aural earphone diperbolehkan sampai 22,4 jam/hari. ${ }^{1}$ Hal penting lain yang perlu diperhatikan adalah suara latar (background noise) saat memakai PLDs dan isolator suara pada earphone. Suara latar yang semakin keras akan meningkatkan tingkat volume suara yang dipilih oleh pemakai PLDs, sedangkan isolator suara yang bagus akan mengurangi suara latar yang masuk ke telinga dan mengurangi kenaikan tingkat volume suara. $^{7}$

Terdapat hubungan yang signifikan antara skor pengetahuan dan skor perilaku $(p=0,000)$ walaupun tingkat korelasinya lemah $(r=0,295)$. Edukasi tentang penggunaan PLDs khususnya kepada pelajar pengguna PLDs diharapkan perilaku akan bertambah baik sehingga tingkat korelasi antara skor pengetahuan dan skor perilaku semakin kuat. Penelitian Taljaard dkk. di Australia pada pelajar usia 9-13 tahun mendapatkan perubahan perilaku dalam pemakaian PLDs secara signifikan setelah dilakukan edukasi dan perilaku tersebut stabil selama pengamatan 3 bulan setelah pemberian edukasi. Sebanyak 15,3\% pelajar yang sebelumnya memakai PLDs pada tingkat volume $75 \%$ dan $10,0 \%$ pada tingkat volume di atas $75 \%$ menurun menjadi masing-masing 5,1\% dan $4,7 \%$ pada 3 bulan setelah edukasi. ${ }^{4}$ Keterbatasan penelitian ini adalah pengambilan sampel dengan cara survey dan pengetahuan awal pengguna PLDs tidak dapat diidentifikasi.

Gangguan pendengaran akibat pemakaian PLDs bersifat permanen. Upaya pencegahan gangguan pendengaran akibat pemakain PLDs harus dilakukan oleh semua pihak yang terlibat. Produsen, penjual, pemerintah melalui dinas kesehatan, pihak sekolah, keluarga, dan seluruh pihak terkait harus memberikan edukasi mengenai bahaya pemakaian PLDs jangka lama. Edukasi yang penting meliputi batasan lama pemakaian PLDs per hari, tingkat volume suara yang aman, jenis earphone yang aman, dan hal yang harus dilakukan bila memakai PLDs pada suasana ramai., ${ }^{1,10}$

\section{SIMPULAN}

Terdapat hubungan antara pengetahuan dengan perilaku dengan tingkat korelasi rendah. Perlu pemberian edukasi terhadap para pelajar terutama pengguna PLDs mengenai pemakaian PLDs yang aman. Diharapkan dengan edukasi yang baik maka pengetahuan dan perilaku pelajar pengguna PLDs semakin baik dan tingkat korelasi semakin tinggi.

\section{DAFTAR PUSTAKA}

1. Breinbauer HA, Anaba JL, Gutierrez D, Olivares C, Caro J. Output capabilities of personal music players and assessment of preferred listening levels of test subjects: outlining recommendations for preventing music-induced hearing loss. Laryngoscope. 2012;122:2549-56.

2. Rahardian J, Prastowo NA, Haryono R. Pengaruh penggunaan earphone terhadap fungsi pendengaran remaja. Maj Kedokt Indon. 2010;60:468-73.

3. Fine N. Critical review: what is the effect of noisy listening 
environments on personal listening levels when using a pers o n a l i s te n i n g d e vice? https://www.uwo.ca/fhs/csd/ebp/reviews/200910/Fine.pdf: University of Western Ontario; 2010.

4. Taljaard DS, Leishman NF, Eikelboom RH. Personal listening devices and the prevention of noise induced hearing loss in children: the cheers for ears pilot program. Noise \& Health. 2013;15:261-8.

5. Dobie RA. Noise induced hearing loss. In: Bailey BJ, Johnson JT, Newlands SD, editors. Head \& neck surgery - otolaryngology. 4th ed. Philadelphia: Lippincott Williams \& Wilkins; 2006.

6. Howard D, McLaren S. Dangerous listening: the exposure of indigenous people to excessive noise. Aboriginal \& Islander Health Worker Journal 2011;35:3-8.
7. Fligor BJ, Ives TE. Does earphone type affect risk for recreational noise-induced hearing loss? In: Fligor BJ, Ives TE, editors. NIHL in Children Meeting; Cincinnati: Etymotic Research; 2007.

8. Peng JH, Tao ZZ, Huan ZW. Risk of damage to hearing from personal listening devices in young adults. J Otolaryngol. 2007;36(3):181-5.

9. Sulaiman AH, Seluakumaran K, Husain R. Hearing risk associated with the usage of personal listening devices among urban high school students in Malaysia. The Royal Society for Public Health. 2013127:710-5.

10. Portnuff CD, Fligor BJ, Arehart KH. Teenage use of portable listening devices: a hazard to hearing? J Am Acad Audiol. 2011;22:663-77. 